\title{
DIREITO AO ESQUECIMENTO: AS APLICAÇÕES DAS DIRETRIZES JURÍDICAS E A INDISPENSABILIDADE DOS DIREITOS DE PERSONALIDADE E LIBERDADE DE EXPRESSÃO
}

\author{
RIGHT TO FORGETFULNESS: THE \\ APPLICATION OF LEGAL GUIDELINES AND \\ THE INDISPENSABILITY OF PERSONALITY \\ RIGHTS AND FREEDOM OF EXPRESSION
}

\section{Gisele Rodrigues Martins Goedert ${ }^{1}$ Victória Alberton Guisi Denke ${ }^{2}$}

Resumo: Este estudo tem por da questão analisada, sendo o objetivo analisar a aplicação do primeiro paradigmático no que direito ao esquecimento nas dire- tange a essa pauta e o segundo trizes jurídicas sob o enfoque da oriundo de recente julgamento colisão de direitos fundamentais, pela Corte Superior de Justiça. considerando os limites consti- Conclui-se com as perspectivas tucionais que desafiam a prática do referido direito junto ao ordedessa garantia a ser dirimido por namento jurídico brasileiro em meio da regra de ponderação. consonância com a Sociedade da Com intuito de promover mate- Informação, pontuando caminhos rialidade a essa discussão, foram a serem trilhados para a busca do colocados dois casos que tratam equilíbrio entre a preservação da

1 Advogada, Mestra em Relações Internacionais para o Mercosul, professora universitária. E-mail:

gisele06@gmail.com

2 Bacharela em Direito pela Universidade do Sul de Santa Catarina (Unisul). E-mail: victoria.alberton@gmail.com 
dignidade humana, fundamento do Estado Democrático de Direito e as garantias às liberdades comunicativas.

Palavras-chave: Direitos fundamentais. Direito ao esquecimento. Colisão de direitos. Regra de ponderação.

Abstract: This study's purpose is to analyze the application of the right to forgetfulness in legal guidelines under the focus of the collision of fundamental rights, considering the constitutional limits that challenge the practice of this guarantee, to be resolved through the weighting rule. In order to promote materiality to this discussion, two cases were raised that deal with the question analyzed, the first being paradigmatic with regard to this agenda and the second, arising from a recent judgment by the Superior Court of Justice. It concludes with the perspectives of the referred law with the Brazilian legal system in line with the Information Society, punctuating paths to be taken into account the search for the balance between the preservation of human dignity, the foundation of the Democratic Rule of Law and the guarantees to freedoms communicative.

Keywords: Fundamental rights. Right to Forgetfulness. Collision of rights. Weighting Rule.

\section{INTRODUÇÃO}

Neste artigo, tratar-se-á do reconhecimento do direito ao esquecimento frente ao conflito entre os direitos de personalidade, que se constituem em direitos fundamentais versus direito à liberdade de imprensa e informação. Para tanto, importa, primeiramente, contextualizar as diretrizes jurídicas do reconhecimento do direito ao esquecimento, visualizando-se, a seguir, a aplicabilidade no ordenamento jurídico brasileiro. Para ilustrar, identifica-se um dos casos emblemáticos e de significativa repercussão nesse sentido, envolvendo Aída Curi, demonstrando as premissas do reconhecimento dessa garantia no Brasil. Por fim, como foco do estudo, será analisado o Recurso 
Especial 1.736.803-RJ, que foi recentemente julgado pelo Superior Tribunal de Justiça e intensifica a discussão sobre a colisão dos direitos de personalidade, a liberdade da informação e as ferramentas as quais o direito dispõe para trazer equilíbrio às relações e proteger a dignidade da pessoa humana.

\section{AS DIRETRIZES JURÍDICAS NO RECONHECIMENTO DO DIREITO AO ESQUECIMENTO}

Nos primórdios, o esquecimento foi utilizado como forma de se evitar atos de vingança após as guerras ao se estabelecer uma ordem de não lembrança dos fatos ocorridos, assumindo uma finalidade de dever, não de direito. É nesse sentido de se combater a vingança com a institucionalização do esquecimento que Rodotá afirma que "a urgência em reagir às tragédias é que induz a pensar que o olhar sobre o passado deva produzir anticorpos capazes de impedir sua repetição no futuro.” (RODOTÁ, 2013).

$\mathrm{O}$ autor sustenta ainda:

Assediados por computadores, espiados por olhos furtivos, filmados por câmeras invisíveis. Os cidadãos da sociedade da informação correm o risco de parecer homens de vidro: uma sociedade que a informática e a telemática estão tornando totalmente transparente. (RODOTÁ, 2008 apud PAESANI, 2014, p. 24).

Nesse sentido, acredita-se que a ideia totalitária do homem de vidro, tendo como raiz o nazismo, pode estigmatizar o homem, retirando-lhe sua dignidade e o direito à privacidade (RODOTÁ, 2013).

Dadas as breves considerações acerca das premissas do direito ao esquecimento, passar-se-á a tratar das suas exordiais manifestações no Brasil. 


\subsection{Direito ao esquecimento no ordenamento jurídico brasileiro}

Neste ponto, serão colocadas concepções referentes ao modo como se entende o direito ao esquecimento e sua aplicabilidade no ordenamento jurídico. Tratando-se da terminologia referente a esse, Pinheiro conceitua-o como
[...] o direito que qualquer ser humano possui de ter qualquer fato vexaminoso ligado a sua vida que afete diretamente sua reputação ser esquecido depois de um determinado lapso de tempo pela população através da não veiculação das informações sobre o fato pelas mí- dias. (PINHEIRO, 2016, p. 490).

Sarlet e Ferreira Neto $(2019$, p. 65) fazem a ressalva para uma melhor denominação dessa garantia, sugerindo a troca de "direito ao esquecimento" por " "direito de não ser forçado a lembrar', 'direito de ser esquecido' ou até mesmo 'direito de silenciar eventos passados que não mais são pertinentes no presente"".

Importa ressaltar, neste sentido, que, em termos de conceito normativo, em referência ao art. 11 do Código Civil (BRASIL, 2002), tem-se o Enunciado 531 da VI Jornada de Direito Civil do Conselho de Justiça Federal, o qual traz em sua redação: "A tutela da dignidade da pessoa humana na sociedade da informação inclui o direito ao esquecimento" e apresenta como justificativa que:

Os danos provocados pelas novas tecnologias de informação vêm-se acumulando nos dias atuais. $\mathrm{O}$ direito ao esquecimento tem sua origem histórica no campo das condenações criminais. Surge como parcela importante do direito do ex-detento à ressocialização. Não atribui a ninguém o direito de apagar fatos ou reescrever a própria história, mas apenas assegura a possibilidade de discutir 
o uso que é dado aos fatos pretéritos, mais especificamente o modo e a finalidade com que são lembrados. (CONSELHO DA JUSTIÇA FEDERAL, 2013).

Pontuadas as concepções adotadas em no território jurídico acerca do direito ao esquecimento, passar-se-á à articulação dessa garantia aquelas inerentes à personalidade, cerne deste artigo.

\subsection{Direito ao esquecimento: direitos fundamentais de personalidade $v s$. direitos às liberdades comunicativas}

Discorrer-se-á, aqui, sobre a inserção do direito ao esquecimento no âmbito dos direitos de personalidade a fim de que se possa compreender o conflito instaurado quando colocado frente a outros princípios fundamentais.

Sérgio Branco (2017) defende que o direito ao esquecimento, caso reconhecido no ordenamento jurídico, deve ser manifestado como direito de personalidade. Esclarece que a falta de previsão do referido direito no rol das garantias ligadas à personalidade do Código Civil não consiste em impedimento para sua previsão.

Na acepção de Paiva (2014), o direito ao esquecimento é primordial para assegurar ao indivíduo a garantia de não ter em poder do conhecimento público fatos psicologicamente desabonadores. O direito aqui estudado, para o autor, tem origem na Constituição e no Código Civil, porquanto vinculado "à dignidade da pessoa humana e do direito à vida privada, à intimidade, à honra e à imagem".

Ademais, conforme transcrito anteriormente, é esse o posicionamento até o momento ponderado pelo Supremo Tribunal Federal no Tema 786, o qual reconhece a garantia em tela como vertente do direito à privacidade. Esse foi ressaltado como consequência dos avanços da sociedade na seara 
constitucional, sendo ainda resultado da necessidade de preencher-se a lacuna que se instaura quando conflitados direitos fundamentais, como a privacidade e a liberdade de expressão e informação. É nesse sentido que Sarlet e Ferreira Neto lecionam, defendendo o esquecimento como "direito especial de personalidade", o qual permite o redesenho de caminhos sem obstáculos colocados pela memória:

O autogoverno da própria memória (passa usar também aqui a acima referida noção de Stefano Rodotà) é, portanto, exigência básica associada à dignidade humana e que como tal carece de reconhecimento e proteção, na condição de direito fundamental. (SARLET; FERREIRA NETO, 2019, p. 125).

Nesse contexto, importa ressaltar, ademais, a estrita aproximação do direito ao esquecimento com os direitos de personalidade, quais sejam, o direito à honra, à imagem, à intimidade e à privacidade. Consoante Reis e Piacentin (2017), aquele direito se constitui em "um direito fundamental implícito", que, juntamente com esses direitos supramencionados, serve como escudo à dignidade da pessoa humana "a fatos banais ou que não servem para o mero deleite do público." (REIS; PIACENTIN, 2017). Na perspectiva de Bezerra Junior (2018), o direito ao esquecimento, quando confirmado no caso concreto, reconhecendo a desnecessidade da permanência de determinada informação acerca da pessoa, daria uma roupagem de "ilicitude da ofensa que se busca coibir", aquela que estava por violar a "honra, o nome, a privacidade e outros direitos da personalidade."

Consoante Sarlet e Ferreira Neto (2019, p. 71), nessa vertente, o direito ao esquecimento tem traços da busca pela "autodeterminação e reconstrução da identidade pessoal", uma vez que busca tutelar as informações divulgadas acerca do indivíduo. Destarte, reconhecido o direito ao esquecimento como garantia fundamental, é mister que se analise a colisão 
entre direitos fundamentais gerada quando se tem, de um lado, o pleito de ser esquecido e, de outro, direitos ligados às liberdades comunicativas. $\mathrm{O}$ direito ao esquecimento, quando pleiteado, divide a balança com os direitos à liberdade de expressão e informação. Com efeito, um direito fundamental não pode ser suprimido em favor de outro sem que, para tanto, haja uma análise do caso concreto para que, por meio do sopesamento, se encontre uma definição do que sustenta aquele direito pleiteado (SILVA, 2006, p. 21).

Quando se fala em colisão de direitos, parte-se do pressuposto de que os direitos fundamentais encontram limites, os quais são estabelecidos por outras garantias previstas constitucionalmente (MENDES; BRANCO, p. 2017). A tutela dos direitos que aqui se apresentou como colidentes, com fulcro na previsão constitucional, não se difere, dando a um ou a outro maior ou menor importância, de forma que se encontram no mesmo patamar de relevância no ordenamento jurídico. Porém, no tocante a outras garantias constitucionais, não tem status de absolutos (SARLET; FERREIRA NETO, 2019, p. 77).

Lembra-se, nesse sentido, ser imprescindível enfatizar o fundamento comum dos direitos que ora se estuda, os quais têm seu alicerce na dignidade da pessoa humana, motivo pelo qual Barcellos (2014) preconiza a inviabilidade de estruturá-los em uma hierarquia inflexível, reconhecendo imperiosa a ponderação dos valores em cada caso concreto pelo Judiciário.

Bezerra Júnior (2018) defende que não se pode perpetuar o "sacrifício de um direito pessoal" que, anteriormente, se legitimava pelo interesse público e que se tornou obsoleto em razão do lapso temporal, devendo-se, então, dar prioridade àquele direito que apresenta maior prestígio na ocorrência da referida hipótese, o direito de desenvolvimento da personalidade do indivíduo. Leciona o autor: 
Nessa quadra, adviria a ilicitude, despida de qualquer excludente, do caráter irrelevante, ou socialmente inútil, adquirido com o transcurso do tempo, da informação perenizada, sem interesse histórico, científico ou público, utilizada em prejuízo de que titulariza os direitos injustamente sacrificados. (BEZERRA JÚNIOR, 2018).

Ao se falar do direito ao esquecimento, é imprescindível que se estude um dos casos pioneiros e emblemáticos no Brasil vinculados a essa matéria. Para tanto, tratar-se-á acerca da ação envolvendo o caso "Aída Curi".

\section{Caso Aída Curi discutido no Recurso Especial 1335.153/RJ}

Esse fato, oriundo de exposição midiática, envolve a TV Globo e esteve sob relatoria do Ministro Luis Felipe Salomão. Os irmãos de Aída Curi, brutalmente assassinada no ano de 1958 ao ser jogada do $12^{\circ}$ andar de um prédio em Copacabana, foram os requerentes da ação de reparação de danos morais, materiais e à imagem proposta contra a emissora.

Alegaram que a Rede Globo reabriu chagas estancadas pelos anos com a transmissão pelo programa "Linha Direta Justiça", no qual rememorava-se fato passado ocorrido com a vítima e a dor suportada pela família. Aduziram, ademais, que tal veiculação do ocorrido na mídia teve objetivo de auferir lucros sobre trágico episódio.

Ante o insucesso nas instâncias ordinárias, os autores recorreram ao Superior Tribunal de Justiça por meio de Recurso Especial buscando a garantia do direito ao esquecimento. $\mathrm{O}$ Ministro Luis Felipe Salomão ressalta, de início, a existência de um conflito de direitos no caso em apreço originados da previsão constitucional, em que há duas vertentes: "de um lado, o legítimo interesse de 'querer ocultar-se' e, de outro, o não menos legítimo interesse de se "fazer revelar." (BRASIL, 2013). 
Em seu voto, o Ministro, em análise da ponderação entre os direitos conflitados, menciona a nobreza do direito ao esquecimento na medida em que significa "[...] na verdade, como um direito à esperança, em absoluta sintonia com a presunção legal e constitucional de regenerabilidade da pessoa humana." (BRASIL, 2013).

Ademais, sustenta-se no acórdão que as vítimas e as pessoas que convivem ao seu redor devem ter reconhecido seu direito ao esquecimento, assim como os condenados que cumprem a pena, de forma que aqueles possam evitar ficar presos a fatos tão pungitivos como pedras amarradas a si que carregam sem nunca poder esquecer de seu peso.

Nesse acórdão, o Ministro afirmou que deve haver uma ponderação da historicidade do fato e de sua repercussão com fito de identificar se se está diante de quebra de limites da mídia para além da informação, o que teria por consequência um erro fundamentado em outro. Nesse sentido, no caso em apreço, votou pelo não provimento do reconhecimento do direito ao esquecimento, na medida em que o lapso de tempo transcorrido entre o fato e a vinculação pela mídia não se configurava em causa de dano moral, negando, então, provimento ao recurso especial.

Os irmãos de Aída prosseguem sua jornada recorrendo ao Supremo Tribunal Federal, por meio do Recurso Extraordinário com Agravo n. 1.010.606, do qual é relator o Ministro Dias Toffoli. Nesse Recurso, foi reconhecida, por maioria de votos, a existência de repercussão geral, conforme a ementa:

DIREITO CONSTITUCIONAL. VEICULAÇÃO DE PROGRAMA TELEVISIVO QUE ABORDA CRIME OCORRIDO HÁ VÁRIAS DÉCADAS. AÇÃO INDENIZATÓRIA PROPOSTA POR FAMILIARES DA VÍTIMA. ALEGADOS DANOS MORAIS. DI- 
REITO AO ESQUECIMENTO. DEBATE ACERCA DA HARMONIZAÇÃO DOS PRINCÍPIOS CONSTITUCIONAIS DA LIBERDADE DE EXPRESSÃO E DO DIREITO À INFORMAÇÃO COM AQUELES QUE PROTEGEM A DIGNIDADE DA PESSOA HUMANA E A INVIOLABILIDADE DA HONRA E DA INTIMIDADE. PRESENÇA DE REPERCUSSÃO GERAL. (BRASIL, 2014).

O referido Recurso Extraordinário, reconhecida a repercussão, teve por objeto o Tema 786, que tem por redação: “O direito ao esquecimento consiste em desdobramento do direito à privacidade, devendo ser ponderado, no caso concreto, com a proteção do direito à informação e liberdade de expressão." (BRASIL, 2014).

Em 12 de junho de 2017, foi realizada audiência pública, convocada pelo ministro relator, que tinha por escopo discutir a incidência do direito que ora se estuda na esfera cível quando esse for suscitado pela vítima ou por seus familiares. Importa aqui mencionar a publicação de manifestação da ProcuradoraGeral da República, Raquel Dodge, no sentido de não reconhecer o direito ao esquecimento no caso em apreço, oportunidade em que se opinou pela necessidade de ponderação entre os direitos conflitados, assinalando que o direito ao esquecimento não se configura em direito absoluto, devendo ser sopesado com o direito à liberdade de expressão. Após manifestação, o Recurso encontra-se concluso ao relator (BRASIL, 2018).

Destarte, com a exposição de um dos casos paradigmáticos do direito ao esquecimento no Superior Tribunal de Justiça, o que se percebe é que se está diante de um conflito muito recente no ordenamento jurídico e que, pelo demonstrado, não se resolve de maneira exata da norma. Na vertente do exposto pelo Ministro Luis Salomão, importa abarcar, neste momento, a regra de ponderação, fórmula que ora parece a mais adequa- 
da para a resolução desse conflito, o qual não permite, a partir de todos os seus meandros, análise de maneira hermética, sem consideração dos variados ângulos contextuais.

\subsubsection{Regra de ponderação}

Os direitos fundamentais podem entrar em colisão, não havendo hierarquia nem anterioridade temporal entre eles, sem prevalência de um sobre o outro. Atento a tal realidade, o $\S$ $2^{\circ}$ do art. 489 do Código de Processo Civil brasileiro (BRASIL, 2015), a exemplo, institui que, no caso de colisão entre normas, o juiz deve justificar o objeto e os critérios gerais da ponderação efetuada, enunciando as razões que autorizam a interferência na norma afastada e as premissas fáticas que fundamentam a conclusão.

A solução que se apresentou adequada para dirimir o choque apresentado é a ponderação entre os princípios colidentes. Nesse sentido, Barroso (2004, apud MALDONADO, 2017, grifo nosso) leciona que:

A colisão de princípios constitucionais ou de direitos fundamentais não se resolve mediante o emprego dos critérios tradicionais de solução de conflitos de normas, como o hierárquico, o temporal e o da especialização. Em tais hipóteses, o intérprete constitucional precisará socorrer-se da técnica de ponderação de normas, valores ou interesses, por via da qual deverá fazer concessões recíprocas entre as pretensões em disputa, preservando o máximo possível do conteúdo de cada uma. Em situações extremas, precisará escolher qual direito irá prevalecer e qual será circunstancialmente sacrificado, devendo fundamentar racionalmente a adequação constitucional de sua decisão.

Sarlet e Ferreira Neto (2019, p. 78-79) corroboram com o entendimento transcrito no que se refere à fundamentação 
pela preferência a um direito, porquanto reconhecem que, no que diz respeito à liberdade de manifestação e expressão, a Constituição já previu expressamente limites ao exercício desse direito. No entanto, no que concerne às garantias ligadas à intimidade e à privacidade, deixou a cargo do julgador ao caso sub judice. Para os autores, tal fato pode ser considerado como um indicativo de que, quanto às liberdades comunicativas, estas precisam de fundamentação deveras significativa para reconhecer-se hipótese para além das previstas no texto constitucional.

Barroso (2018, p. 379) instrui que, para a aplicação da regra de ponderação, deve-se caminhar por três pontos que têm fundamento no princípio da proporcionalidade ou razoabilidade: a) o primeiro passo consiste no reconhecimento do conflito entre normas aplicáveis ao caso; b) após, dever-se-á analisar o caso concreto e a relação deste com as normas suscitadas, aqui se oportuniza ao julgador o esclarecimento do efeito concreto que os princípios levantados têm na situação prática; c) na concepção do autor, é nesse ponto que reside a consolidação da ponderação, pois, nessa etapa, será sopesado o valor intrínseco das garantias apresentadas, alcançando-se determinado resultado pelo reconhecimento de uma ou de outra. Neste momento, urge ressaltar que, nos termos do exposto pelo doutrinador, deve-se ponderar ainda a "intensidade da solução escolhida", estabelecendo-se o âmbito de alcance da prevalência daquela norma no caso concreto.

A base no princípio da proporcionalidade ou da razoabilidade define o caminho para que, seguindo os referidos passos, se conserve, na medida do possível, os valores assegurados pelos direitos ponderados.

No âmbito do conflito que ora se busca solucionar, Sarlet e Ferreira Neto $(2019$, p. 76$)$ reconhecem o direito ao esque- 
cimento como "ponto de equilíbrio" para conciliar a testilha imposta entre os direitos ligados à personalidade e aqueles ligados à liberdade de expressão, porquanto, ao mesmo tempo que está vinculado ao direito ao desenvolvimento da personalidade e sua identidade, por outro lado tenta garantir que o pleito pelo reconhecimento desses não viole o bem jurídico do interesse público.

Para concluir a questão da ponderação dos princípios envolvidos intrinsecamente com o direito ao esquecimento, destaca-se o preconizado por Bezerra Júnior (2018) no que diz respeito à prevalência do interesse público frente ao direito de privacidade ou à honra, defendendo-se, nesse sentido, o "princípio do mínimo dano" para o qual não se permite abusos na vinculação da informação sobre o indivíduo envolvido.

Dessa forma, ultrapassada a questão da solução a ser adotada quando configurado o conflito entre os direitos de personalidade e liberdade de expressão, passar-se-á à análise dessa adversidade jurídica em um caso concreto a fim de que se torne mais palpável todo o arcabouço teórico aqui discorrido.

\subsection{Análise da decisão envolvendo o "direito ao esquecimento" no Superior Tribunal de Justiça}

Neste ponto, será trazida à baila ação referente ao conflito entre direitos fundamentais vinculados à personalidade e às liberdades comunicativas com o intuito de ilustrar a materialidade de toda a discussão efetivada no transcorrer deste estudo. Um dos aspectos fulcrais da abordagem a seguir são informações das pessoas veiculadas no espaço midiático que promovem contínuas rememorações dos fatos, os quais estão vivos, sendo acionados mediante simples digitação de alguns caracteres, integralmente, sem fronteiras. Trata-se, pois, de colisão entre a necessidade que a sociedade possui de receber informações e o direito que o ser humano tem de resguardar sua identidade, de- 
letando lembranças que o impedem de soltar as âncoras de sua vida para continuar sua trajetória em todos os âmbitos.

Outro ponto a salientar-se é a forma como os casos estão sendo compreendidos nas instâncias jurídicas, sendo reconhecida a imprescindibilidade de aprofundar o conhecimento de todas as perspectivas dos cenários em análise, percebendo-se a maneira pela qual está sendo viabilizado o reconhecimento do direito ao esquecimento no ordenamento jurídico em consonância com as demais liberdades fundamentais que alicerçam o Estado Democrático.

Para tanto, o enfoque dar-se-á em julgado do Superior Tribunal de Justiça, o Recurso Especial 1.736.803-RJ, de modo a perceber-se como o direito ao esquecimento assume expressiva preponderância no atual contexto da Sociedade da Informação.

\subsubsection{Recurso Especial 1.736.803-RJ}

O presente caso originou-se na "ação de obrigação de fazer e não fazer c/c indenização por danos morais" proposta por $P$. N. P., S. R. R. P., F. N. P., T. N. P. e V. N. P., sendo os menores representados por seu genitor S. R. R. P contra a Tres Editorial LTDA. - em recuperação judicial. A demanda originou-se após publicação de matéria jornalística na revista "ISTO É" com a manchete "Exclusivo, A Vida Após a Cadeia, Como Vivem Hoje os Assassinos Famosos Condenados por Crimes que Chocaram o País", no mês de outubro de 2012, que abordava, além da imagem, a vida das pessoas que foram condenadas por crimes de homicídio marcantes para a sociedade, a rotina dessas e de seus familiares, levando a público informações pessoais e, primordialmente, lembrança do crime cometido nos idos dos anos 90.

A autora alegou a violação do seu direito à imagem, porquanto estampada em capas de revistas sem sua autorização, 
bem como teve que lidar com a exposição excessivamente onerosa de fatos da sua vida.

No juízo de primeira instância, o pleito teve parcial procedência, posto que se condenou a ré ao pagamento de indenização por danos morais no quantum de 30.000,00 (trinta mil reais) à primeira autora e $\mathrm{R} \$ 20.000,00$ (vinte mil reais) aos demais requerentes. Em segunda instância, utilizada a regra de ponderação entre direitos fundamentais, decidiu-se por afastar o direito ao esquecimento com fundamento na não acepção da censura prévia e somente se modificou o termo inicial para contagem dos juros de mora, computando-se desde o fato danoso.

Irresignados, recorreram ao Superior Tribunal de Justiça alegando violação aos dispositivos que resguardam os direitos de personalidade, bem como aqueles garantidos pela Lei $\mathrm{n}$. 7.210/1987, quais sejam, o direito do preso de ser protegido contra sensacionalismos e a garantia de não serem divulgadas publicamente informações sobre a condenação após extinta a pena. Ademais, alegaram o rompimento das previsões de proteção à criança e ao adolescente estabelecidas na Lei n. 8.069/1990. Buscam, assim, a reforma do acórdão da Décima Quinta Câmara Cível do Tribunal de Justiça do Rio de Janeiro, a fim de verem satisfeitas as pretensões de que a ré deixasse de publicar matérias relacionadas ao crime cometido pela autora, bem como o pleito de majoração da indenização por dano moral.

O Recurso Especial 1.736.803-RJ de relatoria do Ministro Ricardo Villas Bôas Cueva configurou a seguinte ementa:

RECURSO ESPECIAL. AÇÃO DE INDENIZAÇÃO POR DANOS MORAIS CUMULADA COM OBRIGAÇÃO DE FAZER E NÃO FAZER. MATÉRIA JORNALÍSTICA. REVISTA DE GRANDE CIRCULAÇÃO. CRIME HISTÓRICO. REPORTAGEM. REPERCUSSÃO NACIONAL. DIREITO À PRIVACIDADE. PENA PERPÉTUA. PROIBIÇÃO. DIREITO À RES- 
SOCIALIZAÇÃO DE PESSOA EGRESSA. OFENSA. CONFIGURAÇÃO. DIREITO AO ESQUECIMENTO. CENSURA PRÉVIA. IMPOSSIBILIDADE. MEMÓRIA COLETIVA. DIREITO À INFORMAÇÃO. LIBERDADE DE EXPRESSÃO. ESPOSO E FILHOS MENORES. EXTENSÃO DOS EFEITOS DA CONDENAÇÃO. PRINCÍPIO DA PESSOALIDADE DA PENA. DIREITO AO DESENVOLVIMENTO INTEGRAL. ESTATUTO DA CRIANÇA E DO ADOLESCENTE. DANO MORAL. VALOR DA INDENIZAÇÃO. REEXAME FÁTICO. VEDAÇÃO. (BRASIL, 2020, grifo nosso).

Sob o enfoque do direito ao esquecimento, discorrendo acerca de suas vertentes, o relator afirma que pode esse decorrer da esfera de proteção de dados pessoais, a qual envolve precipuamente a rede, ou da ruptura de garantias fundamentais, perspectiva que abrange o caso levado à Corte de Justiça. Anota o reconhecimento do direito ao esquecimento no mencionado Enunciado n. 531 da VI Jornada de Direito Civil do Superior Tribunal de Justiça, que vem sendo invocado na proteção dos direitos da personalidade vilipendiados nas exposições imoderadas de crimes cometidos cuja pena já se cumpriu objetivamente, mas com marcas que permanecem sempre ao dispor de julgamentos aos olhos furtivos dos meios midiáticos (CONSELHO DA JUSTIÇA FEDERAL, 2013).

O Ministro relator traz ao cerne do julgado seu entendimento do direito ao esquecimento como a garantia do indivíduo de não ter divulgado fatos desabonadores sobre si que não mais tenham relevante carga de interesse público e ressalta a ponderação entre os direitos conflitados como instrumento a ser utilizado para juízo do caso em exame. Anota-se que ponderação dos direitos deve sempre fundamentar-se no princípio da proporcionalidade (SARLET; MARINONI; MITIDIERO, 2018, p. 505). Quer-se, com isso, afirmar que deve ser levada em consideração a ne- 
cessidade que, nas palavras de Mendes e Branco (2017), “[...] vale dizer, se for imaginável outra medida que renda o resultado esperado, mas com menos custo para o indivíduo".

Insculpido no art. $5^{\circ}$, inciso XIV, da Constituição Federal (BRASIL, 1988), o direito à informação é a prerrogativa que:

[...] todos os seres humanos têm de obter informações ou conhecimentos para satisfazer às suas necessidades de saber, compreender as faculdades de buscar ou procurar e receber informações, o que equivale afirmar que a pessoa pode estar informada tanto por ter pesquisado, como por the haver sido dada a informação. (SILVA, 1779 apud BITTELI, 2004, p. 26).

Desse modo, para que o direito à comunicação seja exercido de acordo com os princípios constitucionais, é indispensável que se leve em conta a objetividade do que se pretende informar, considerando os interesses daqueles que serão receptores da mensagem a ser transmitida, de modo a evitar-se duplicidades e interpretações duvidosas dos fatos noticiados (FARIAS, 2004, p. 164-165).

$\mathrm{O}$ que se infere, segundo o relator, do acervo probatório amealhado nos autos é que a publicação pela revista de matéria de cunho sensacionalista tem nítido esvaziamento comunicacional porquanto nenhum conteúdo informativo traz com a exposição da vida dos recorrentes, sendo antagônico querer afirmar que a reportagem ancora-se no direito à informação. Ao revés, fundamenta-se em nítido clamor e espetacularização ao vincular-se a manchete supracitada, que se julga válido retomar: "Exclusivo, A Vida Após a Cadeia, Como Vivem Hoje os Assassinos Famosos Condenados por Crimes que Chocaram o País".

$\mathrm{Na}$ análise do jurista, tal artifício desperta na sociedade o sentimento de que a condenação, ainda que cumprida e extinta, não se faz legítima, visto que a autora de crime de in- 
contestável repercussão leva uma vida comum, com rotinas igualmente comuns. Importa, desse modo, transcrever valoroso trecho do julgado:

Ao se debruçar sobre o papel da mídia como mecanismo de atualização e reforço à sociedade punitiva, o jurista e sociólogo David Garland afirma que "o discurso da mídia e da criminologia popular apresenta os criminosos como 'diferentes', e menos que totalmente humanos", apagando e naturalizando dimensões relevantes da persecução penal e de suas consequências (GARLAND, 1995, p. 243 apud BRASIL, 2020).

É nesse contex to que se insere a espetacularização do crime, em que o leitor assume uma posição de observador e apreciador da fragilidade humana. Esse movimento sensacionalista, que desperta o clamor público, já era enfrentado no século anterior e foi analisado por Cervini:

[...] os comunicadores tentam ganhar expectação e diversão pintando a criminalidade como algo inaudito, enigmático, sinistro, extraordinário e misterioso. $\mathrm{O}$ acontecimento criminal é grotesco; suscita um agradável estremecimento de horror, faz possíveis a complacência e a altivez moralizantes do não criminal, que pode destacar-se do autor do fato punível (CERVINI, 1994 apud BUDÓ, 2008).

Há fatos que, ao serem transformados em notícias, se constituem em potencial arma condenatória daquele que está envolvido nas circunstâncias explicitadas e, não raramente, o clamor da sociedade atua como promotor de situações que podem trazer desgaste da honra e até perda de determinados papéis sociais do indivíduo, sendo, portanto, imprescindível a atuação do Estado para equilibrar as forças nesse contexto.

O estigma social carregado por aquele que cometeu ilícito penal em algum momento passado encontra sustentáculo na 
perpetuidade das lembranças desabonadoras de sua personalidade sempre destacadas pela mídia, ultrapassam-se as grades físicas e passa-se a conviver com muros sociais. Conforme discorre Gonçalves (2015, p. 207), “o direito de estar só, de se isolar, de exercer as suas idiossincrasias se vê hoje, muitas vezes, ameaçado pelo avanço tecnológico". Significa dizer, pois, que a pessoa se encontra cercada de situações que a cerceiam em sua individualidade, impedindo-a, grande parte das vezes, de tornar-se visível em sua singularidade.

Ao finalizar a análise pontual da questão levantada quanto ao conteúdo da matéria jornalística e a vedação à estigmatização e à pena perpétua, o Ministro reconhece posição profana ao fundamento do Estado Democrático de Direito, ao desprezar-se os direitos assegurados ao condenado reabilitado, aqui já mencionado o retorno ao convívio social, bem como a vedação à perpetuidade das penas.

Contudo, apesar do reconhecimento das mencionadas violações, julga o relator não ser concebível reconhecer-se o direito ao esquecimento, pois não se pode impor à editora que deixe de publicar notícias vinculadas ao ato criminoso sob pena de adentrar-se no campo da censura prévia ao suprimir o direito à liberdade de expressão.

Nesse sentido, nas palavras de Travassos (2013, p. 301):

O que evidentemente deve ser evitado é a censura prévia de publicações. Representaria odioso retrocesso no sistema pluralista democrático brasileiro, que, via de regra, deve-se reconhecer e igualmente defender. Medidas extremadas não necessariamente demandam soluções extremadas.

Não se pode correr o risco de asfixiar a atual Constituição retomando o peso de chumbo vigente no período anterior à abertura democrática, sobre o qual discorreu Agra (2018): 
Os direitos e garantias constitucionais se tornaram deleites formais para estudiosos, porque na realidade o que predominava era o autoritarismo, a censura e, o que foi mais grave, a tortura. Aqueles que tivessem a ousadia de discordar do regime eram perseguidos, o direito de reunião e de liberdade de expressão foram arrefecidos. As suspensões dos direitos e garantias fundamentais eram feitas em nome da "segurança nacional." (AGRA, 2018).

$\mathrm{O}$ direito à liberdade de expressão encontra-se previsto no rol do art. $5^{\circ}$ da Constituição Federal (BRASIL, 1988), conforme se lê: "IV - é livre a manifestação do pensamento, sendo vedado o anonimato". Além desse, outros artigos da Lei Maior buscam tutelar a referida garantia em suas diversas acepções, sendo essas decorrentes da "cláusula geral" que se configura esse dispositivo (SARLET; MARINONI; MITIDIERO, 2018, p. 498).

A liberdade de expressão busca resguardar o direito de opinar amplamente e formar juízo sobre coisas e pessoas. Segundo Mendes e Branco (2017), “incluem-se na liberdade de expressão faculdades diversas, como a de comunicação de pensamentos, de ideias, de informações, de críticas, que podem assumir modalidade não verbal (comportamental, musical, por imagem etc.)".

Ainda na acepção desses autores, a qual é reiterada no juízo do caso em exame, o direito fundamental aqui discorrido tem por primordial objetivo exigir do Estado que se abstenha de praticar a censura. Dessa afirmação, colhe-se o art. 220 da Constituição Federal (BRASIL, 1988), que dispõe: "a manifestação do pensamento, a criação, a expressão e a informação, sob qualquer forma, processo ou veículo não sofrerão qualquer restrição, observado o disposto nesta Constituição".

Agra (2018), em sua obra, acentua a diferença entre a liberdade de expressão e a liberdade de comunicação. Esta tem o 
viés de notícias e ocorridos, ao passo em que a outra consiste, como já mencionado anteriormente, na expressão de opiniões e julgamentos pela pessoa. $\mathrm{O}$ autor destaca que o direito à liberdade de expressão se legitima a partir do direito de informação.

Ante a inexistência de direitos absolutos, a liberdade de expressão também encontra limites de incidência. Sobre restrições, importa mencionar que essa liberdade somente pode acontecer quando houver explicitação do pensamento; enquanto este não for externalizado, não há que se falar em limites (AGRA, 2018).

O direito à informação, in casu, encontra fundamento no fato de que o crime cometido pela primeira recorrente supera a esfera da curiosidade individual do leitor acerca do noticiado, pois, além de envolver pessoas publicamente conhecidas e ter ampla notoriedade à época, foi o impulsor para a tipificação como hediondo do crime de homicídio qualificado (art. $1^{\circ}$, inciso I, da Lei n. 8.072/1990). Dessa forma, entendeu o relator não haver arcabouço legítimo para que se viole a memória coletiva nem para que se rompa a história do progresso deveras significativo da lei penal. A respeito, argumenta o Ministro Ricardo Villas Bôas Cueva:

Quanto ao ponto, destaca-se a exposição de Daniel Sarmento, em audiência pública promovida pelo Supremo Tribunal Federal convocada em decorrência do Recurso Extraordinário $n^{\circ} 1.010 .606 / R J$. Em suas palavras, “o direito ao esquecimento é antônimo da história”, fato preocupante em um país marcado pela amnésia coletiva. Por esse motivo, tal direito não poderia ser "invocado, para impedir divulgação e discussão de fatos verídicos, apenas porque acontecidos no passado" (disponível em http://www.stf.jus.br/portal/cms/verNoticiaDetalhe.asp?idConteudo=346380) (BRASIL, 2020).

Por fim, adverte o jurista que a vedação à censura prévia não afasta a garantia de recorrer-se à análise da publicação 
de divulgações que atentem a honra dos indivíduos. No conceito de Bittar (2015, p. 201-202), "o direito à honra - que goza de espectro mais amplo -, o bem jurídico protegido é a reputação, ou a consideração social a cada pessoa devida, a fim de permitir-se a paz na coletividade e a própria preservação da dignidade humana". Entendendo-se que a opinião pública é bastante influenciável a determinadas notícias, ressaltando-se aquelas mais nefastas, é mister que o cabedal jurídico atue como mecanismo de proteção a essas pessoas que entram no foco de notícias e informações menos favoráveis a seu respeito.

Ao fim, não acolhido o pleito de desvinculação da reportagem que envolve os recorrentes, passou-se a discorrer sobre o princípio da intranscedência da pena, bem como a violação a fundamentos do Estatuto da Criança e do Adolescente.

A Carta Magna, em seu art. $5^{\circ}$, inciso XLV, garante que "nenhuma pena passará da pessoa do condenado, podendo a obrigação de reparar o dano e a decretação do perdimento de bens ser, nos termos da lei, estendidas aos sucessores e contra eles executadas, até o limite do valor do patrimônio transferido." (BRASIL, 1988).

No caso em exame, ao abordar aspectos familiares da vida da primeira recorrente, a publicação infringiu o princípio da intranscedência penal, porquanto aqueles que fazem parte de sua vida tiveram que amargar os efeitos da estigmatização gerada pela condenação criminal. Resulta que aqueles do círculo de convivência do autor da infração respondem também pelo ato praticado, pois lidam com as consequências de um passado timbrado.

Também, no contexto dos fatos, se tem a agravante de se ter envolvido, no inconsequente espetáculo midiático, menores de idade, quais sejam, os filhos da primeira autora, maculando 
também a honra de crianças que acabam condenadas, ainda que inimputáveis penalmente, violando-se, assim, dispositivos que protegem a personalidade desses indivíduos preconizados no Estatuto da Criança e do Adolescente.

Por fim, argumenta-se sobre o pleito de revisão do quantum indenizatório por danos morais, vez que alegam os recorrentes ser o valor arbitrado distante do real aplicado pelas Cortes de Justiça em julgados semelhantes.

Para o ministro relator, não há que se falar em novo arbitramento de indenização, pois não podem os valores de $\mathrm{R} \$$ $30.000,00$ (trinta mil reais) determinados para a primeira autora e de $\mathrm{R} \$ 20.000,00$ (vinte mil reais) para os outros recorrentes serem considerados irreais para reparar o dano sofrido. As quantias vão ao encontro daquelas fixadas em casos análogos no Superior Tribunal de Justiça.

Por fim, destacou o julgador ser desacertado o pleito de indenização com base no faturamento da editora, pois não é critério para se alcançar o caráter pedagógico de que não se reitere a conduta praticada, em equilíbrio com o combate ao enriquecimento ilícito.

Enfim, negou-se provimento aos pleitos do Recurso Especial por unanimidade da Terceira Turma após voto-vista da Ministra Nancy Andrighi, restando, portanto, claramente demonstrada a busca por um equilíbrio das garantias testilhadas no caso apreciado ao aplicar-se a regra de ponderação, instrumento defendido por Travassos (2014, p. 301):

Proporcionalidade e Razoabilidade deverão sempre nortear o exercício da ponderação, de modo a permitir a tomada de decisões serena e balizada na necessária distribuição de pesos entre os princípios em rota de colisão, para o fim de se permitir, na medida do necessário, a valoração de sua intensidade perante o caso concreto. 
Representa, portanto, valioso mecanismo jurídico quando está em um dos lados da balança, o direito ao esquecimento.

\section{CONCLUSÃO}

Dando concretude ao caminho palmilhado, entende-se que se faz urgente, diante do cenário vivenciado, o reconhecimento, no ordenamento jurídico pátrio, do direito ao esquecimento nos termos do Tema 786 articulado com o Enunciado 531 da VI Jornada de Direito Civil do Conselho de Justiça Federal, ponderando, no caso concreto, a possibilidade de aplicação da referida garantia, a fim de permitir ao indivíduo livrar-se dos grilhões que o prendem aos fatos pretéritos que não têm mais significativa relevância para ser assegurado como conteúdo do direito à liberdade de expressão (CONSELHO DA JUSTIÇA FEDERAL, 2013).

Para minimizar o agravo ao sujeito preso às memórias midiáticas, passou-se a aplicar a regra de ponderação nas ocorrências que acabam por desaguar no Judiciário. Resta claro que não se deve analisar tais situações atendo-se às amarras da letra da lei, sendo necessário buscar o equilíbrio entre os interesses colidentes a fim de que se possa contemplar, no caso concreto, o direito que, ante as circunstâncias, se apresenta como mais valoroso a ser protegido pelo Estado.

Percebeu-se, neste estudo, a viabilidade do reconhecimento do direito ao esquecimento mediante questões constitucionais que o acompanham, entendendo que a negação dessa garantia pode gerar a impossibilidade ao cidadão de retomar sua jornada, impedindo-o de prosseguir e reinserir-se socialmente, não o visibilizando em seu direito mais precioso, a dignidade.

Vislumbrou-se, diante da investigação, a necessidade de se embrenhar em estudo contínuo e consistente para que todas as instâncias sejam preservadas e consideradas, garantindo-se a 
aplicabilidade dos direitos fundamentais previstos constitucionalmente, de forma a dar primazia à dignidade humana, purificando sistematicamente os ares dos ambientes jurisdicionais.

\section{REFERÊNCIAS}

AGRA, Walber de Moura. Curso de direito constitucional. 8. ed. Belo Horizonte: Fórum, 2018. E-book.

BARCELLOS, Ana Paula. Intimidade e pessoas notórias. Liberdades de expressão e de informação e biografias. Conflito entre direitos fundamentais. Ponderação, caso concreto e acesso à justiça. Tutelas específica e indenizatória. Revista de Direito Público, Brasília, v. 11, p.4791, jan. 2014. Disponível em: https://www.portaldeperiodicos.idp.edu. br/direitopublico/article/view/2372/1236. Acesso em: 17 maio 2020.

BEZERRA JÚNIOR, Luis Martius Holanda. Direito ao esquecimento: a justa medida entre a liberdade informativa e os direitos da personalidade. 1. ed. São Paulo: Saraiva Educação, 2018. E-book.

BITTAR, Carlos Alberto. Os Direitos da personalidade. 8. ed. São Paulo: Saraiva, 2015. E-book.

BRANCO, Sérgio. Memória e esquecimento na internet. Porto Alegre: Arquipélago Editorial, 2017. E-book.

BRASIL. [Constituição (1988)]. Constituição da República Federativa do Brasil de 1988. Brasília, DF: Presidência da República, 1988. Disponível em: http://www.planalto.gov.br/ccivil_03/constituicao/ constituicaocompilado.htm. Acesso em: 12 maio 2020.

BRASIL. Lei no 10.406, de 10 de janeiro de 2002. Institui o Código Civil. Brasília, DF: Presidência da República, 2002. Disponível em: http://www.planalto.gov.br/ccivil_03/leis/2002/L10406.htm. Acesso em: 13 maio 2020.

BRASIL. Lei $\mathbf{n}^{\mathbf{0}} \mathbf{1 3 . 1 0 5}$, de 16 de março de 2015. Código de Processo Civil. Brasília, DF: Presidência da República, 2015. Disponível em: http://www.planalto.gov.br/ccivil_03/_ato2015-2018/2015/lei/113105. $\mathrm{htm}$. Acesso em 20 de maio de 2020.

BRASIL. Lei $\mathbf{n}^{\mathbf{0}} \mathbf{1 3 . 7 0 9 ,} 14$ de agosto de 2018. Dispõe sobre a proteção de dados pessoais e altera a Lei ${ }^{\circ} 12.965$, de 23 de abril de 2014 
(Marco Civil da Internet). Brasília, DF: Presidência da República, 2018. Disponível em: http://www.planalto.gov.br/ccivil_03/_ato2015 2018/2018/lei/L13709.htm . Acesso em: 16 maio 2020.

BRASIL. Superior Tribunal de Justiça (3. Turma). Recurso Especial n. 1.736.803-RJ. Relator: Ministro Ricardo Villas Bôas Cueva. 28 de abril de 2020. Disponível em: https://ww2.stj.jus.br/processo/revista/ documento/mediado/?componente=ITA\&sequencial=1910273\&num registro $=201700267279 \&$ data $=20200504 \&$ formato $=$ PDF. Acesso em: 14 maio 2020.

BRASIL. Superior Tribunal de Justiça (4. Turma). Recurso especial n. 1.335.153- RJ. Relator: Ministro Luis Felipe Salomão. 28 maio de 2013. Disponível em: https://ww2.stj.jus.br/processo/revista/documento/mediado/?componente $=$ ITA\&sequencial $=1237428 \&$ num_registro $=201100574280 \&$ data $=20130910 \&$ formato $=P D F$. Acesso em: 12 maio 2020.

BRASIL. Supremo Tribunal Federal. Recurso Extraordinário n. 1.010.606. Relator: Ministro Dias Toffoli. 18 de novembro de 2014. Disponível em: http://www.stf.jus.br/portal/jurisprudenciaRepercussao/verAndamentoProcesso.asp? incidente $=5091603 \&$ numeroProcesso $=1010606 \&$ classeProcesso $=\mathrm{RE} \&$ numeroTema=786. Acesso em: 22 maio 2020.

BUDÓ, Marília Denardin. O Espetáculo do crime no jornal: da construção social da criminalidade à relegitimação do sistema penal. In: CONGRESSO LATINO-AMERICANO DE DIREITOS HUMANOS E PLURALISMO JURÍDICO, 2008, Florianópolis. Anais [...]. Florianópolis: UFSC, 2008. Disponível em: http://www. egov.ufsc.br/portal/sites/default/files/anexos/33470-43144-1-PB. pdf. Acesso em: 20 maio 2020.

CONSELHO DA JUSTIÇA FEDERAL. Enunciado n. 531. A tutela da dignidade da pessoa humana na sociedade da informação inclui o direito ao esquecimento. In: JORNADA DE DIREITO CIVIL, 6.,2013, Brasília. Anais [...]. Brasília, DF: CJF, 2013. Disponível em: http://www.cjf. jus.br/cjf/corregedoria-da-justica-federal/centro-de-estudos-judiciarios1/publicacoes-1/jornadas-cej/vijornadadireitocivil2013-web.pdf. Acesso em: 11 maio 2020.

FARIAS, Edilsom. Liberdade de expressão e comunicação: teoria e proteção constitucional. São Paulo: Revista dos Tribunais, 2004. 
GONÇALVES, Carlos Roberto. Direito civil brasileiro: parte geral. 13. ed. São Paulo: Saraiva, 2015. 1. v. E-book.

MALDONADO, Viviane Nóbrega. Direito ao esquecimento. Barueri: Novo Século, 2017. E-book.

MENDES, Gilmar Ferreira; BRANCO, Paulo Gustavo Gonet. Curso de direito constitucional. 12. ed. São Paulo: Saraiva, 2017. E-book.

PAESANI, Liliana Minardi. Direito e internet: liberdade de informação, privacidade e responsabilidade civil. 7. ed. São Paulo: Atlas, 2014. E-book.

PAIVA, Bruno César Ribeiro de. O direito ao esquecimento em face da liberdade de expressão e de informação. Revista Jurídica do Ministério Público do Estado de Minas Gerais, Belo Horizonte, v. 13, n. 22, 2014. Disponível em: https://aplicacao.mpmg.mp.br/xmlui/handle/123456789/1202. Acesso em: 19 maio de 2020.

PINHEIRO, Patricia Peck. Direito digital. 6. ed. São Paulo: Saraiva, 2016. E-book.

REIS, Jordana Maria Mathias dos; PIACENTIN, Antônio Isidoro. Direito ao esquecimento como um direito fundamental. Revista Eletrônica do Mestrado em Direito da Ufal, Maceió, v. 8, p.71-85, jan. 2017. Disponível em: http://www.seer.ufal.br/index.php/rmdufal/article/view/3365/2771. Acesso em: 24 maio 2020.

RODOTÁ, Stefano. O direito à verdade. Civilistica.com., Rio de Janeiro, ano 2, n. 3, p. 1-22 jul./set. 2013. Disponível em: http://civilistica.com/o-direito-a-verdade/. Acesso em: 12 maio 2020.

SARLET, Ingo Wolfgang; FERREIRA NETO, Arthur M. O Direito ao esquecimento na sociedade da informação. Porto Alegre: Livraria do Advogado, 2019.

SARLET, Ingo Wolfgang; MARINONI, Luiz Guilherme; MITIDIERO, Daniel. Curso de direito constitucional. 7. ed. São Paulo: Saraiva Educação, 2018. E-book.

SILVA, Virgílio Afonso da. O conteúdo essencial dos direitos fundamentais e a eficácia das normas constitucionais. Revista de Direito do Estado, São Paulo, v. 4, p.23-51, 2006. Disponível em: https://constituicao.direito.usp.br/wp-content/uploads/2006-RDE4-Conteudo_essencial.pdf. Acesso em: 18 maio 2020. 
TRAVASSOS, Marcela Maffei Quadra. Hatespeech e liberdade de expressão. In: SCHREIBER, Anderson (coord.). Direito e mídia. São Paulo: Atlas, 2013. p. 281-303. E-book.

Recebido em: 28/05/2020

Aprovado em: 16/07/2020 